\title{
A FILOSOFIA EM MEIO À EDUCAÇÃO PROFISSIONAL TÉCNICA NOS INSTITUTOS FEDERAIS DO BRASIL
}

\author{
PHILOSOPHY IN PROFESSIONAL TECHNICAL EDUCATION AT THE BRAZILIAN \\ FEDERAL INSTITUTES \\ LA FILOSOFÍA EN MEDIO DE LA EDUCACIÓN PROFESIONAL TÉCNICA EN LOS \\ INSTITUTOS FEDERALES DE BRASIL
}

Fausto dos Santos Amaral Filho ${ }^{1}$

Joelson Juk ${ }^{2}$

\begin{abstract}
${ }^{1}$ Doutor em Filosofia (UFRJ). Docente do Programa de Pós-Graduação em Educação da Universidade Tuiuti do Paraná (UTP), Curitiba, PR, Brasil.
\end{abstract}

${ }^{2}$ Doutorando em Educação pela Universidade Tuiuti do Paraná (UTP), Curitiba, PR, Brasil.

Resumo: O texto investiga a educação profissional técnica nos Institutos Federais do Brasil em uma perspectiva de crítica filosófica. Parte-se do surgimento dos Institutos Federais em um contexto liberal positivista, para se pensar a tecnocracia e a especialização na constituição do modelo social e pedagógico presente nessas instituições de ensino. Por conseguinte, a reflexão recai sobre o papel que pode ser desempenhado pelo ensino da Filosofia na defesa da educação profissional técnica integral em contraponto com a educação profissionalizante de caráter liberal positivista. Busca, assim, contribuir para o fortalecimento de um projeto de educação profissional técnica integral.

Palavras-chave: Educação Profissional; Filosofia; Institutos Federais.

Abstract: This text studies the professional technical education of the Brazilian Federal Institutes from the perspective of a philosophical critique. It starts with emergence of the Federal Institutes in a positivist liberal context, linking it to technocracy and expertise in the social and pedagogical model present in those institutions. This reflection then turns to the role of the teaching of Philosophy in defense of professional technical education with a integral formation against the professional education from a positivist liberal point of view. Thus, this study seeks to contribute to strengthening an integral professional technical education.

Keywords: Professional Education; Philosophy; Federal Institutes.

Resumen: El texto investiga la educación profesional técnica en los Institutos Federales de Brasil en una perspectiva de la crítica filosófica. Empezamos con la aparición de los Institutos Federales en el contexto liberal positivista, para pensar en tecnocracia y experiencia en la creación del modelo social y pedagógico existente en estas instituciones educativas. Consecuentemente, el reflejo es sobre el papel que puede desempeñar la enseñanza de la filosofía en defensa de la educación profesional técnica integral en contraposición a la formación profesional de carácter liberal positivista. Buscando así contribuir con la consolidación de un proyecto de educación profesional técnica integral.

Palabras clave: Educación Profesional; Filosofía; Institutos Federales. 


\section{INTRODUÇÃO}

A educação, em sentido amplo, pode ser definida como o conjunto de saberes construídos no convívio coletivo circunscrito em determinado espaço-tempo. Caracterizando-a, assim, como o processo relacional de aprendizagem e de ensino. Desse processo, resultam as construções materiais e imateriais, as criações de organizações civis e de Estado, as disputas pelos recursos naturais, o domínio da informação e do conhecimento, os períodos de guerra e de paz entre os povos, entre outros. A educação pauta a identidade humana e, portanto, só se pode desvendar essa identidade fazendo um significativo esforço intelectual.

A educação profissional técnica, em uma consideração preliminar, se define por um conjunto menor de saberes da educação geral, o qual é destinado aos diferentes exercícios de trabalho nas sociedades humanas. Ocorre em diversos ambientes formais e informais, com múltiplos graus de organização, distintos meios e finalidades. Ao desenvolver a qualificação de um aprendiz ou veterano em determinado ofício, potencializa sua presença na coletividade em um novo patamar de força e poder social. A educação profissional técnica, portanto, conforme previsto nas diretrizes e nas bases da educação nacional, no artigo 36-A e ss. da Lei 9.394 de 20 de dezembro de 1996, vincula-se ao mundo do trabalho e ao todo das práticas sociais decorrentes.

Apresentam-se esses conceitos, inicialmente, para que o escopo do presente trabalho seja compreendido em sua correta extensão: a investigação sobre a educação profissional técnica nos Institutos Federais do Brasil. Primeiramente, será analisado o surgimento dos Institutos Federais em um contexto liberal positivista, para se entender as bases de pensamento e do modelo educacional profissional pretendido na sociedade brasileira. Em seguida, será avaliado o surgimento da ideologia tecnocrática nas sociedades modernas, para se identificar a racionalidade própria da industrialização, instauradora de modificação nas relações dos homens entre si e com a técnica. Depois, será estudado o surgimento da ideologia da especialização nas sociedades modernas, para se aferir em que medida os homens modificam seu modo de ser e agir em determinada função organizacional, a de especialista. Por fim, serão apresentados os elementos para uma crítica da educação profissional técnica nos Institutos Federais brasileiros, como contribuição para o avanço das discussões acerca da visão de educação integral.

\section{OS INSTITUTOS FEDERAIS EM UM CONTEXTO LIBERAL POSITIVISTA}

Essa investigação analisa as bases políticas e epistemológicas que sustentam o projeto de criação e instalação dos Institutos Federais do Brasil, por serem instituições pertencentes à Rede Federal de Educação Profissional e Tecnológica, criada pela Lei 11.892 de 29 de dezembro de 2008, vinculada ao Ministério da Educação por meio da Secretaria de Educação Profissional e Tecnológica, composta por 38 unidades independentes. 
Os Institutos Federais se originaram de Escolas Técnicas Federais ou de Centros Federais de Educação Tecnológica. A Lei 6.545 de 30 de junho de 1978 instituiu os Centros Federais de Educação Tecnológica, e o Decreto 7.566 de 23 de setembro de 1909 criou as Escolas de Aprendizes e Artífices para o ensino profissional primário gratuito. Essas instituições escolares sofreram modificações administrativas e pedagógicas para adaptar-se às demandas da sociedade brasileira. São casos ilustrativos disso as transformações do Centro Federal de Educação Tecnológica do Paraná em Universidade Tecnológica Federal do Paraná, pela Lei 11.184 de 07 de outubro de 2005 e da Escola Técnica da Universidade Federal do Paraná em Instituto Federal do Paraná, pela Lei 11.892 de 29 de dezembro de 2008.

Foi no início do século XX que a ideia de transformar a sociedade brasileira, por intermédio da educação profissional escolar, deu seus primeiros passos. Um século depois, o que era uma ideia se transformou em um projeto consolidado. É preciso entender que foram os ideais republicanos positivistas, proclamados em 1889, que alimentaram a crença na educação profissional escolar como fator de regeneração do tecido social e base para o desenvolvimento econômico-industrial. Com o fim do regime de escravidão, o mercado de mão de obra livre passou a ser questão de primeira ordem para a nascente República Federativa do Brasil. A educação profissional escolar associava-se, pois, às teorias políticofilosóficas dessa época as quais chegavam ao Brasil oriundas, fundamentalmente, da Europa: especificamente, o positivismo de Auguste Comte, bem demarcado em obras como Plano de Trabalho Científico para Reorganizar a Sociedade (1822), Curso de Filosofia Positiva (18301842) e Discurso sobre o Espírito Positivo (1848).

O cientificismo que sustenta esse pensamento cunhava no país a mentalidade da classe dominante, representada por alcunhas como Benjamin Constant, Campos Sales, Deodoro da Fonseca, Quintino Bocaiúva, Floriano Peixoto, Nilo Peçanha e Ruy Barbosa. Crescia fortemente a ideia de que o desenvolvimento econômico-social passaria inevitavelmente pela inserção do Brasil no cenário mundial por meio de uma rápida saída da economia agrária para a economia de mercado industrializado. Nesse sentido,

\footnotetext{
a República passaria a considerar, dentro dos parâmetros do pensamento liberal, o trabalho 'como condição intrínseca ao homem que só se desenvolvendo, possibilita a criação dos bens morais, pois recupera e eleva o sentido ético dos indivíduos e dos bens materiais'. O acúmulo de bens morais e materiais formaria a riqueza da nação. (QUELUZ, 2000, p. 17).
}

É assim que a educação, sobretudo profissional escolar, passou a ser vista pelas classes hegemônicas como um mecanismo eficiente para o desenvolvimento da nova sociedade brasileira. Acima de tudo, viu-se no pensamento liberal positivista um projeto para a sociedade democrática de consenso, que desconhece o conflito de classes como um motor da história humana. Em outros termos:

os ideais e aspirações, contidos no sistema social democrático, envolvem a igualdade rigorosa de oportunidades entre todos os indivíduos, o virtual desaparecimento das desigualdades econômicas e uma sociedade em que a felicidade dos homens seja amparada e facilitada pelas formas mais lúcidas e mais ordenadas. (TEIXEIRA, 1968, p.149).

Em síntese, identificamos na origem dos Institutos Federais as bases de um pensamento liberal e de um modelo hegemônico de educação profissional técnica positivista. Com isso, 
não afirmamos absolutamente que essas instituições não possuem outras maneiras de pensar administrativa ou pedagogicamente. O que identificamos historicamente nelas é uma herança intensamente assinalada pelas ideologias da tecnocracia e da especialização, resultantes do modus faciendi dos processos de produção industrial que, inseridos no ensino escolar dos Institutos Federais, assemelham-se ao ensino fabril.

\section{OS INSTITUTOS FEDERAIS E A IDEOLOGIA TECNOCRÁTICA}

No século XV vemos o início do declínio do paradigma medieval, do modo de saber filosófico-teológico que identificava a intencionalidade do sobrenatural como a chave de compreensão ou desvendamento da existência humana e, por conseguinte, do mundo. A suprema alteridade, que é o ser divino, por si só explicava a existência em suas diferentes manifestações. Ao ser humano competia a contemplação e a reverência tanto de Deus quanto daqueles que o representavam na Terra. Assim, à racionalidade humana compete captar a intencionalidade do criador em seu movimento decisório e realizador, cabendo-lhe compreensão e obediência. Transferência de poder significa abdicação de responsabilidade sobre seu destino. Daí entendemos, nessa época, por que eram valorizadas as atividades contemplativas, os conhecimentos metafísicos, a economia feudal, as formas teocráticas de governo, as tradições familiares do campo, as verdades reveladas pelos livros sagrados, entre outros. Não havia a preocupação, como regra, de que o ser humano se ocupasse com a apreensão ou a descoberta dos segredos das coisas, da matéria, da concretude do mundo.

Com o declínio deste período, esse modo de saber e, consequente, o governo do mundo vigente que lhe era adequado começaram a sofrer gradativas e profundas alterações chamadas de renascentistas. Na elaboração do pensamento dos autores do período isso fica evidente. Vejamos o que afirma Bacon: "que o gênero humano recupere os seus direitos sobre a natureza, direitos que lhe competem por doação divina. Restitua-se ao homem esse poder e seja o seu exercício guiado por uma razão reta e pela verdadeira religião." (BACON, 1997, p. 98). Para o autor, a interpretação é a obra verdadeira e natural da mente, o que mostra uma ruptura com a ideia da mente subordinada aos desígnios da revelação divina: "consideramos a mente não meramente pelas faculdades que lhe são próprias, mas na sua conexão com as coisas, devemos presumir que a arte da invenção robustecer-se-á com as próprias descobertas." (BACON, 1997, p. 98).

Podendo ser considerado o primeiro dos modernos e último dos antigos, Bacon contribuiu para a nascente ciência empírica e a passagem do pensamento teocêntrico para o humanista. Assim confirma Comte: "desde essa época memorável, o movimento de ascensão da filosofia positiva e o movimento de decadência da filosofia teológica e metafísica foram extremamente realçados." (COMTE, 1996, p. 28). A intencionalidade da natureza passou a ser perseguida como necessária e suficiente para o entendimento sobre o ser humano e o mundo. Verificamos isso nas transformações culturais, econômicas, éticas, morais, políticas e religiosas, baseadas no fundamento racional e não mais espiritual. Interessa-nos, sobretudo, no período, a transição do feudalismo para o capitalismo. 
A racionalidade capitalista, no século XVIII, provocou uma nova configuração do mundo com o fenômeno da industrialização/fabricação. A utilização de maquinaria em larga escala, a apropriação sem precedentes das fontes naturais de energia, o uso do trabalho assalariado e de métodos científicos para controle da produção e do trabalho, demarca esse novo tempo. A racionalidade do cálculo começou a predominar sobre a racionalidade da tradição medieval. A matriz da cultura antropocêntrica ocupou o espaço da matriz teocêntrica.

A industrialização alterou a estrutura e o funcionamento dos países, o modo de vida agrário foi substituído pelo urbano, o trinômio capital-mercadoria-trabalho efetivou-se, as comunicações e os transportes ganharam nova abrangência, as ciências exatas ou empíricoformais atingiram o ápice na escala de explicação/governo do mundo e, em contrapartida, as ciências humanas ou abstratas foram acusadas de refrear as descobertas tecno-científicas. $\mathrm{O}$ desenvolvimento da grande indústria nos mostra que,

[...] a criação da riqueza efetiva passa a depender menos do tempo de trabalho e do quantum de trabalho empregado que do poder dos agentes postos em movimento durante o tempo de trabalho, poder que [...], por sua vez, não tem nenhuma relação com o tempo de trabalho imediato que custa sua produção, mas que depende, ao contrário, do nível geral da ciência e do progresso da tecnologia, ou da aplicação dessa ciência à produção. (MARX, 2011, p. 587-8).

A criação da riqueza na sociedade moderna passou a ser impulsionada por um novo motor: a tecnocracia. Tal racionalidade tecnocrática alterou a cosmovisão humana, manifestando exponencialmente uma ideologia positiva. O saber positivo, em alguma medida, foi incorporado ao padrão societário como expressão de uma nova destinação. A razão humana foi afetada pela eficácia instrumental dos métodos de governo da vida. O lógos que estava no espaço de domínio do saber filo-teológico, desde a Antiguidade, foi incorporado na matriz da ciência moderna, recebendo novos contornos e finalidades.

No modo de saber científico moderno, a tecnocracia positivista apropriou-se da ação e da consciência humana com desempenho e velocidade jamais vistos. O ponto de apoio do mundo até então assentado nos desígnios divinos avoca outra base de sustentação, a racionalidade instrumental. A consequência imediata dessa guinada na intencionalidade se traduz no seguinte: o humano reverencia a si mesmo e, portanto, assume a responsabilidade por sua destinação. No movimento de autoexpressão, o saber daí decorrente ultrapassa a mera contemplação do mundo. A mentalidade científica nascente exige uma postura agressiva em relação ao cosmos que se descobre. Apreender o mundo significa também envolvê-lo hermeticamente em um saber positivo. O lógos unifica o conhecimento íntimo da matéria/ coisa na intencionalidade humana. Com esse saber científico, o projeto humano se desloca das ideias metafísicas para as ideias positivistas,

enfim, no estado positivo, o espírito humano, reconhecendo a impossibilidade de obter noções absolutas, renuncia a procurar a origem e o destino do universo, a conhecer as causas íntimas dos fenômenos, para preocupar-se unicamente em descobrir, graças ao uso bem combinado do raciocínio e da observação, suas leis efetivas, a saber, suas relações invariáveis de sucessão e de similitude. (COMTE, 1996, p. 22-3).

Não se trata de uma visão otimista romântica e sim pragmática. A razão humana inaugura para si uma época e a potência dessa conquista reside na confiança da sua autoexpressão e autorrealização. Para garantir o êxito gradativo, contínuo e linear desse projeto, a linguagem 
matemática assume uma função central. Por isso nos diz Lukács que "a essência do cálculo racional assenta, afinal de contas, no facto de se conhecer e prever o curso que inevitavelmente tomarão os fenômenos, de acordo com as leis e independentemente do arbítrio individual." (LUKÁCS, 1989, p. 112).

A métrica utilizada para dimensionar o mundo físico serviu ainda para medir as competências e as habilidades humanas. Os dados numéricos das formas, aos poucos, passaram para os conteúdos. Não bastava mais observarmos e analisarmos as qualidades da matéria. Antes, era necessário quantificá-la por um determinado método - divisão, enumeração, ordenação, revisão - e por meio de instrumentos específicos - astrolábio, balança, luneta, metro, relógio, termômetro. Para elucidar: a matéria possui certa existência ou propriedade qualitativa, mas isso não significa que possua uma essência imaterial.

Por esse entendimento, a medida se tornou a ferramenta padrão mais eficiente de conhecer a matéria como se apresenta ao ser humano. Forma e conteúdo são vistos como um só. Existe a coisa. Não existe a essência puramente intelectiva da coisa. Assim, a medida isolada não exprime a concretude da matéria e deve ser transformada em uma equação. É a equação que exprime em relações métricas que explicam a matéria, em seu movimento específico de existência, captando a sua constituição aparente, seu ciclo e tempo de existência, seu lugar e função no mundo. Assim, percebemos que entre a estrutura quantificável da matéria e a intencionalidade humana há um ponto em comum: a tecnocracia. O poder da técnica aqui entendido não como resultado de uma vontade divina, mas como efeito colateral do pouco cuidado do saber em construção.

A tecnocracia comporta a ideia de que o poder manipulativo do mundo está na criação e não no criador. A transferência desse poder é que dá o controle do lógos para a criação. O criador perde o lógos. Mais do que isso, passa a ser seu escravo. O espanto no mundo moderno, com o anúncio de tal poder científico, foi notável, pois

a aplicação técnica é a forma social e a verdade social da ciência moderna, de um conhecimento científico pautado pela primeira ruptura epistemológica. 0 conhecimento científico produz-se separando-se dos saberes locais, e é também separado deles que se aplica às práticas onde eles circulam. Correspondentemente, o modo de racionalidade da comunidade científica sobrepõe-se ao modo de racionalidade das comunidades de saber local. (SANTOS, 1989, p. 163).

A autossuficiência da técnica, portanto, resulta na alienação humana do seu destino e é aí que a crítica filosófica deve ser acentuada. Ao que tudo indica, pelas palavras de Adorno, aquele conhecimento que pretendia controlar o mundo parece estar, ele mesmo, fora de controle: "o mundo está tão completamente determinado pela técnica, que se desenvolveu além das previsões." (ADORNO, 1986, p. 63). Por isso, cabe ao ser humano "mudar seu comportamento, vigiando e controlando a própria atividade técnica, que, apresentando à primeira vista só utilidade, pode levar em seu bojo, a curto ou a longo prazo, os efeitos negativos e desastrosos." (NOGARE, 1988, p. 318).

Pela tecnocracia, o saber não pensa a si mesmo e o poder não controla a si mesmo. É a constatação mais evidente. Mais do que isso: o desenvolvimento do saber técnico 
desvinculado da intencionalidade humana provoca uma insensibilidade com a vida humana na medida em que a matéria passa a assumir características humanoides e o humano passa a ter características de coisa. O ser humano é esquecido, de algum modo, na coisificação de sua autoexpressão. Como efeito preocupante, há uma inversão no mundo: a relação técnicahomem passa para o plano existencial principal e a relação humano-humano para o plano existencial secundário.

Em termos pedagógicos, nos Institutos Federais, esse pensamento tecnocrático se fez sentir na quase totalidade do espaço curricular para as disciplinas técnicas, o que favoreceu uma cultura de incompreensão do saber humanístico. A reprodução do saber, a repetição de fórmulas ou certezas, a supervalorização das investigações empíricas, entre outros, favoreceram uma geração de estudantes com deficit no desenvolvimento das competências e das habilidades, alicerçadas na reflexão sobre os problemas da vida, do mundo do trabalho, da diversidade cultural, enfim, da complexidade da vida privada e profissional.

\section{OS INSTITUTOS FEDERAIS E A IDEOLOGIA DA ESPECIALIZAÇÃO}

Como o aparelho ideológico sustenta o aparelho econômico, pela racionalidade instrumental, o que se segue é a materialização da ideia em um empreendimento concreto: a empresa. Notemos que a empresa pode ser: agrícola, comercial, escolar, extrativista, fabril, financeira, política, sindical. Notemos, também, que a empresa provoca o surgimento de construções, equipamentos, instrumentos, máquinas, moedas, títulos. Mas, antes de qualquer coisa, percebamos que a empresa viabiliza a ideia liberal e, ao mesmo tempo, dela se sustenta como intencionalidade civilizatória. O ser-indivíduo se faz ser-coletivo na empresa.

A dissociação entre o indivíduo, a empresa e a sociedade liberal, portanto, é incongruente. O indivíduo personifica a ideia liberal em determinada empresa da sociedade liberal. Missão, visão e valores são atribuições dadas às empresas, na sociedade liberal capitalista, exatamente por essa razão. O indivíduo é coisificado. A empresa é personificada. A sociedade é reificada. Não há espaço para a contradição entre os elementos em relação. A racionalidade instrumental, de alguma forma, liga os elementos e instiga a interdependência, como meio de perenidade.

A seleção, o recrutamento e o treinamento de empregados nas empresas - e o ensino nos Institutos Federais -, por isso mesmo, não podem ser desvinculados dos valores da sociedade liberal. Tanto na empresa como nos Institutos Federais, o fio condutor que relaciona o ser-indivíduo ao ser-coletivo é a função desempenhada. A competência funcional não deve ser entendida apenas como qualificação teórica da ação, mas sim a ação concreta necessária e/ou suficiente do ser humano, que o qualifica e o quantifica na produção de resultados. O desempenho decide a abrangência vivencial para a realização individual, identifica a aderência aos princípios institucionais e ao espaço-tempo adequado para a exploração de suas potencialidades. A função manifesta ao máximo a destinação, a etapa evolutiva e o lócus do individual na coletividade. 
Por essas razões, é que na composição da sociedade liberal e de suas respectivas empresas, as funcionalidades vão além dos manuais de conduta (éticos ou técnicos), tomando o centro das determinações vivenciais e das escolhas profissionais. O conteúdo próprio da função, nesses ambientes institucionais, é o perfil profissional que define a designação organizacional. Em outros termos, o ser-indivíduo passa a ter certa qualidade de pertencimento ao projeto institucional e isso termina por delimitar o espaço profissional, sua agregação ou cooptação.

A função expressa o lugar do indivíduo no ambiente, suas determinações, competências e, por fim, sua destinação organizacional. Indica sua extensão no mundo, aquilo que realiza como determinação do destino concreto, ou seja, como resposta à sua responsabilidade no mundo. Isso explica como o tempo é escasso na empresa. Muitas são as determinações ou as responsabilidades funcionais a serem atendidas: ambição, comunicação, especialização, imaginação, informação, inovação, motivação, organização, entre outras. E, dentre elas, a que eleva ao máximo o ser-indivíduo ao ser-coletivo é a especialização.

Mas não devemos definir a função do especialista na empresa capitalista ou nos institutos federais, por atributos meramente particulares do indivíduo-especialista. Isso camufla o que lhe está por trás: seus predicados se originam da formação da consciência socialmente construída. Os atributos de especialização manifestados nas atividades sociais ou profissionais respondem às exigências da racionalidade instrumental na modernidade. Isso implica afirmar,

assim como o sistema capitalista se produz e reproduz economicamente a uma escala cada vez mais alargada, também, no decurso da evolução do capitalismo, a estrutura da reificação penetra cada vez mais profundamente, fatalmente, constitutivamente, na consciência dos homens. (LUKÁCS, 1989, p. 108).

De um ponto de vista imediato e genérico, o especialista está presente em toda a rede de relações e realizações, sendo a expressão máxima do saber positivo. Nos diversos empreendimentos humanos (arte, ciência, comunicação, demografia, economia, justiça, legislação, política, religião), a voz e o poder de decisão passam pelo indivíduo-especialista: para definir o valor de uma obra de arte; diagnosticar um enfermo; falar sobre liberdade de expressão; estabelecer políticas de controle populacional; prever o futuro das finanças; sentenciar alguém por seus atos; criar uma lei específica; defender uma ideia; religar o humano à divindade.

Não podemos entender esse apoderamento, essa potência de existir, como se fosse mera qualidade inata ou de seleção natural. Conforme Habermas, "a razão, enquanto razão instrumental, assimilou-se ao poder, renunciando desta forma à sua força - esta é a última desocultação de uma crítica da ideologia aplicada a si mesma." (HABERMAS, 1998, p. 120). Nessa perspectiva, a individualidade representa a submissão da racionalidade aos valores liberais tecnocráticos. Esses valores, como matrizes da ação e do pensamento, ao mesmo tempo, sintetizam a matriz do poder social e a incapacidade reflexiva do ser humano ideologizado.

O ser-especialista é uma consequência existencial da moderna racionalidade instrumental e os empreendimentos que realiza ou faz realizar, vincula-se à formação das ideias fundantes de uma crença liberal no poder do eu sobre o nós, do subjetivo sobre o objetivo, da parte sobre o todo, da unidade sobre o conjunto.

Tais ideias atingem a estrutura e o funcionamento das instituições e o destino das atividades humanas. Para exemplificar, vale a análise dos produtos e dos serviços, que são 
conformados pela determinação do indivíduo-especialista. Para cada defeito de um produto, um perito específico é contratado. Para cada parte do corpo humano, existe um médico próprio. Se o clima está fora de controle, há um conhecedor do tempo. Se a empresa vai mal na concorrência, um consultor resolve. O time de futebol corre o risco de ser rebaixado, o técnico renomado reverte. Aqui chegamos ao ponto de um alerta: o império dos especialistas não é perfeito. Um número indefinido de especialistas fracassam por não atenderem a todas as pressões e exigências desse modelo liberal. Mas esses são deixados de lado. São considerados exceções à regra. Não ofuscam a ideia reinante da especialização.

A autonomia do conceito de especialista transcende os entraves e as exceções. Com a habilidade de dominar a estrutura e o funcionamento de um produto, procedimento ou comportamento, o ser-especialista acaba por controlar uma parte de sua realidade concreta. Com esse controle estabelecido passa a ter o respeito de seus semelhantes, se tornando referência profissional. A diferenciação salarial, as formas de contrato, o espaço de atuação e o tipo distinto de relação com a chefia são as expressões mais aparentes de reconhecimento. Aquele que alcança esse poder organizacional recebe a autorização exclusiva para manipular instrumentos e máquinas de alto valor material e simbólico, acessa ambientes que seus pares não conseguem com chaves e códigos que lhe são confiados, distribui tarefas consideradas menos relevantes aos outros não especialistas, sustenta maior capacidade de negociação de seu destino profissional em momentos de crise financeira ou institucional.

O saber do ser-generalista não foi extinto nas organizações, não é isso. Quando uma fábrica deixa de funcionar e as causas são desconhecidas, todos os entes são estimulados ou compelidos a procurar a solução ou as soluções. Os generalistas trazem sugestões, opinam, trocam ideias, de alguma forma participam do restabelecimento das atividades próprias das empresas ou dos Institutos Federais. Todavia, é ao ser-especialista que recorremos para a solução do problema. Sobre ele recaem as expectativas e as pressões que visam à solução imediata da questão. É ele que mantém o foco no problema. Isto quer dizer que a ideologia do especialista, sobretudo, é de matriz cultural liberal. Resultante do otimismo racionalista moderno, tal qual confessa Vieira Pinto: "ao pensar-se a si mesmo nesta perspectiva, o homem descortina no plano mais alto do pensamento a sua origem no processo universal, e começa a conceber as leis da realidade deste processo como as que conferem realidade a ele mesmo." (VIEIRA PINTO, 1979, p. 213-4).

Desse poder da ideia do especialista depende a sobrevivência do modo de operação das instituições que reduzem a destinação humana à dimensão do cálculo. Por trás do otimismo que recai sobre o ser-especialista está a expressão sinistra da utilidade humana, a precisão dos resultados, a eficiência dos meios, o domínio psicofísico, o controle do tempo-espaço, o domínio dos sonhos. O ser-especialista não surge do além: sobre isso é necessário pensar, dizer e reafirmar. A ideologia do especialista se oculta para não revelar sua origem na tecnocracia.

\section{OS INSTITUTOS FEDERAIS E A FILOSOFIA}

A análise direcionada à tecnocracia e à especialização, até aqui, expõe as bases de uma compreensão intelectiva filosófica crítica sobre a herança liberal positivista na educação 
profissional técnica, presente nos Institutos Federais. Essa análise provoca a desconfiança na razão instrumental, desocultando os interesses evidentes e subjacentes, que sustentam um pensamento reducionista e mecanicista do ensino técnico. Defendemos a Filosofia para repensar essa realidade educacional concreta, em vista da modificação do status quo, que se revela obstáculo para uma formação técnica integral, em uma perspectiva de emancipação humana. Assim ensinam Adorno e Horkheimer: "a filosofia não é síntese, ciência básica ou ciência-cúpula, mas o esforço de resistir à sugestão, a decisão resoluta pela liberdade intelectual e real." (ADORNO; HORKHEIMER, 1985, p. 227). Assim, a Filosofia apresenta-se como uma oportunidade para a reflexão crítica.

A Filosofia necessita irromper os fatos revestidos de destino, para que a razão se torne autônoma e criadora, capaz de eliminar a contaminação da fatalidade. Por pretendermos um saber crítico, no contexto imanente do ser humano racional, carece seguir nesse caminho de abertura. Isso condiz com a promessa feita em seu surgimento nos períodos míticos da Grécia Antiga, de ser ruptura e não mera continuidade. Essa promessa, como verificamos ao longo dos tempos, constitui sua legitimação. Eis aí a explicação razoável que fundamenta a necessidade da presença da Filosofia ainda hoje: crítica que não se configura ou se estrutura como pura abstração contemplativa. Na verdade, se manifesta como potencialidade para se encontrar o télos de qualquer atividade humana. A educação, sem dúvida, pode ser esse télos.

A crítica filosófica cumpre esse papel, na medida em que denuncia a tecnocracia e a especialização como amarras para a formação técnica integral, já que geram certo estado de alienação e de individualismo. Nesses estados, o ser em formação técnica se encontra envolto em um determinismo tecnicista que lhe impede de compreender o significado mais profundo da profissão, a construção do coletivo. Para sair desses estados de consciência, é necessário um esclarecimento, que, para Kant, "significa a saída do homem de sua minoridade, pela qual ele próprio é responsável. A minoridade é a incapacidade de se servir de seu próprio entendimento sem a tutela de um outro." (KANT, 2005, p.63).

No estado de esclarecimento, o profissional atinge a reflexão crítica e se liberta do estado de reprodução, torna-se capaz de transcender a realidade vivida para a realidade pensada. A formação baseada na simples observação sensorial, no laboratório, na prática afastada da teoria, no apego ao instrumental e na repetição de comportamentos, carece de sentido. O esclarecimento proporciona a dúvida nos modos de ser e de agir. Como saber pensado, provoca a luta contra os mecanismos de alienação da vida, os conhecimentos superficiais do mundo e a traiçoeira segurança das leis naturais. A técnica pela técnica desmorona. "aqui se tem em mira a possibilidade de a civilização mundial, assim como apenas agora começou, superar algum dia seu caráter técnico-científico-industrial como única medida da habitação do homem no mundo." (HEIDEGGER, 1996, p. 99).

Pelo pensar livre, portanto autêntico, o sistema de crenças do profissional começa a ser questionado. Compreendendo suas influências, se apodera do próprio destino. As verdades até então estabelecidas, como a neutralidade e a objetividade das ciências, passam para o campo da dúvida. Outras verdades, como a intencionalidade e a subjetividade, passam para o campo das possibilidades. Nesse momento, a formação humanista toma o lugar da formação tecnicista. 
Mas como provocar essa mudança na educação profissional técnica, especialmente nos Institutos Federais? Para Bazzo, podemos falar que "a 'filosofia da tecnologia' surge em função de uma nova dinâmica que move o ser humano, em que os problemas filosóficos estão mesclados com as técnicas industriais de base científica e com as suas repercussões sobre o meio ambiente e o meio social que delas farão uso." (BAZZO, 2011, p. 130). Sabemos que este campo da filosofia não é de fácil implantação e as resistências dos profissionais de engenharia, tecnologia e cientistas em geral serão sentidas com força. "No entanto, esta mudança é incontestável e deve-se, sem dúvida, à própria transformação experimentada pela ciência e pela tecnologia - aliás, transformação devida àqueles mesmos que negam a importância de uma análise não tão mecanicista sobre suas criações - e ao destaque que adquiriram no mundo atual." (BAZZO, 2011, p. 130).

A resistência aponta para os defensores da formação profissional técnica anti-humanista, inibidora da reflexão filosófica. Todavia, sobretudo, fortalece os defensores da formação profissional técnica integral com processos formativos humanísticos e técnicos, contrários entre si, mas não contraditórios; diferentes, mas não excludentes.

\section{CONCLUSÃO}

Com a expectativa e o horizonte da reflexão, os pesquisadores adentraram na realidade dos Institutos Federais do Brasil, apresentando-a em um determinado contexto e rejeitando a mera constatação de fatos históricos. A partir de uma inquietação intelectual, identificaram as ideologias da tecnocracia e da especialização como produtos de uma sociedade liberal positivista, que merece apontamentos filosóficos críticos no sentido de sua superação.

Evidenciamos que a razão filosófica provoca a desconfiança na razão instrumental, na medida em que chama a atenção para os interesses evidentes ou subjacentes que sustentam o pensamento positivista do mundo e da educação profissional, de caráter tecnicista. Sabendo disso, queremos provocar o debate sobre os conhecimentos considerados essenciais para uma formação técnica integral: epistemologia, estética, ética, lógica, metafísica, política e técnica.

O resultado do trabalho, em última instância, visa alcançar o discernimento dos agentes públicos que administram, executam, organizam ou pensam os projetos pedagógicos de cursos técnicos. Daí a defesa de uma educação profissional técnica integral, do homem como um zoon politikon, cujo lócus privilegiado seja o pensamento esclarecido, que cumpre a função histórica de revelação do entorpecimento da mentalidade técnica. Apontamos, desse modo, para a direção da intervenção filosófica na construção de uma proposta educacional com duas frentes de atuação: por um lado, o fortalecimento das políticas de obrigatoriedade do ensino das humanidades nos cursos técnicos e, por outro lado, a discussão sobre a equação desfavorável entre as disciplinas técnicas e humanísticas nos projetos pedagógicos de cursos técnicos. É uma tarefa desafiadora nas pesquisas acadêmicas, pois consiste em pôr em evidência que a formação de profissionais críticos, autônomos e empreendedores, necessita de bases epistemológicas e pedagógicas que transcendam as competências e/ou as habilidades meramente empírico-formais. 


\section{REFERÊNCIAS}

ADORNO, T. Capitalismo Tardio ou Sociedade Industrial? In.: COHN, G. (Org.). Sociologia: Theodor Adorno. São Paulo: Ática, 1986.

BACON, F. Aforismos sobre a interpretação da natureza e o reino do homem - livro I. São Paulo: Nova Cultural, 1997. (Coleção Os pensadores).

BRASIL. Decreto 7.566 de 23.09.1909. Cria nas capitais dos Estados da Escolas de Aprendizes Artífices, para o ensino profissional primário e gratuito, 1909. Disponível em: <http://portal.mec.gov. br/setec/arquivos/pdf3/decreto_7566_1909.pdf>. Acesso em: 18 out. 2016.

BRASIL. Lei 6.545 de 30.06.1978. Dispõe sobre a transformação das Escolas Técnicas Federais de Minas Gerais, do Paraná e Celso Suckow da Fonseca em Centros Federais de Educação Tecnológica e dá outras providências, 1978. Disponível em: <http://www.planalto.gov.br/ccivil_03 /leis/L6545. htm>. Acesso em: 18 out. 2016.

BRASIL. Lei $\mathbf{n}^{\circ} \mathbf{9 . 3 9 4}$ de 20.12.1996. Estabelece diretrizes e bases da educação nacional, 1996. Disponível em: <http://www.planalto.gov.br/ccivil_03/leis/19394.htm>. Acesso em: 18 out. 2016.

BRASIL. Lei 11.184 de 07.10.2005. Dispõe sobre a transformação do Centro Federal de Educação Tecnológica do Paraná em Universidade Tecnológica Federal do Paraná e dá outras providências, 2005. Disponível em: <http://www.planalto.gov.br/ccivil_03/_Ato 2004-2006/2005/Lei /L11184. htm >. Acesso em: 18 out. 2016.

BRASIL. Lei $\mathbf{n}^{\circ} \mathbf{1 1 . 8 9 2}$ de 29.12.2008. Institui a Rede Federal de Educação Profissional, Científica e Tecnológica, cria os Institutos Federais de Educação, Ciência e Tecnologia, e dá outras providências, 2008. Disponível em: <http://www.planalto.gov.br/ ccivil_03/_ato20072010/2008/lei/ I11892.htm>. Acesso em: 18 out. 2016.

BAZZO, W. A. Ciência, tecnologia e sociedade: e o contexto da educação tecnológica. 3. ed. rev. Florianópolis: UFSC, 2011.

COMTE, A. Curso de filosofia positiva. Trad. José Arthur Giannotti e Miguel Lemos. São Paulo: Nova Cultural, 1996. (Coleção Os pensadores)

HABERMAS, J. O Discurso Filosófico da Modernidade. Lisboa: Dom Quixote, 1998.

HEIDEGGER, M. O fim da filosofia e a tarefa do Pensamento. São Paulo: Nova Cultural, 1996.

HORKHEIMER, M.; ADORNO, T. Dialética do esclarecimento: fragmentos filosóficos. Rio de Janeiro: Jorge Zahar, 1985.

KANT, I. Resposta à pergunta: Que é “Esclarecimento"? 3. ed. Petrópolis: Vozes, 2005.

LUKÁCS, G. História e consciência de classe: estudos de dialética marxista. 2. ed. Rio de Janeiro: Elfos, 1989.

MARX, K. Grundrisse: manuscritos econômicos de 1857-1858 - Esboços da crítica da economia política. São Paulo: Boitempo, 2011.

NOGARE, P. D. Humanismos e anti-humanismos: introdução à antropologia filosófica. 11. ed. rev. e ampl. Petrópolis: Vozes, 1988.

QUELUZ, G. L. Concepções de Ensino Técnico na República Velha (1909-1930). Curitiba: Cefet-PR, 2000. 
SANTOS, B. S. Introdução a uma Ciência Pós-Moderna. 6. ed. Porto: Afrontamento, 1989.

TEIXEIRA, A. Pequena introdução à filosofia da educação: a escola progressiva ou a transformação da escola. 5. ed. São Paulo: Cia. Editora Nacional, 1968.

VIEIRA PINTO, A. Ciência e Existência: problemas filosóficos da pesquisa científica. 2. ed. Rio de Janeiro: Paz e Terra, 1979.

Artigo recebido em: 19/02/2018 Aprovado em: 15/03/2018

Contato para correspondência:

Joelson Juk.

E-mail: joelson.juk@ifpr.edu.br 